\title{
Analysis of Durability and Shrinkage Properties of HPC Applicable to Nuclear Power Plants by Replacement of Mineral Admixtures
}

\author{
Eun-A Seo \\ Structural Engineering Research Institute \\ Korea Institute of Civil engineering and Building technology \\ Goyang, South Korea \\ E-mail: sea0524@ kict.re.kr \\ Neung-won Yang \\ Structural Engineering Research Institute \\ Korea Institute of Civil engineering and Building technology \\ Goyang, South Korea \\ E-mail: neungwon@kict.re.kr
}

\author{
Jang-Hwa Lee \\ Structural Engineering Research Institute \\ Korea Institute of Civil engineering and Building technology \\ Goyang, South Korea \\ E-mail: jhlee@kict.re.kr \\ Do-Gyeum Kim * \\ Structural Engineering Research Institute \\ Korea Institute of Civil engineering and Building technology \\ Goyang, South Korea \\ E-mail: dgkim@kict.re.kr
}

\begin{abstract}
In this study, we evaluated the durability and the shrinkage of concrete mixes for constructing nuclear power plant structures, prepared by replacing some of the concrete with diverse admixtures. The experiment variables were the types of admixtures and the replacement rate, and mixing of the two-component and three-component system concrete was carried out. The parameters for evaluating concrete durability were compressive strength, salt damage resistance, and freezing and thawing resistance that are the major durability characteristics for nuclear power plant structures, and measurements were made till the material age of 91 days. Though most mixes showed freezing and thawing resistance performances equal to or better than that of the existing concrete mix for nuclear power plants, the freezing and thawing resistance was affected considerably by the air content of the concrete rather than by the types of the admixtures and the replacement rate. Further, the concrete produced by replacing some of the cement with fly ash was found to have better salt damage resistance than the concrete produced by replacing some of the cement with blast furnace slag. The measured durability of the concrete produced by replacing some of the concrete with blast furnace slag was found to be higher than that of the existing concrete mix for use in the construction of nuclear power plants.
\end{abstract}

Keywords-HPC; Shrinkage; Durability; Freezing and Thawing Resistance Performance; Mineral Admixture;

\section{INTRODUCTION}

Nuclear power plants are in the spotlight as they are environmentally friendly and have the advantages that their resource efficiency is higher than that of petroleum power plants and their carbon dioxide emission is lower by about $1 \%$. For this reason, about 430 nuclear power plants are in operation at present, and about 150 nuclear power plants are planned to be constructed worldwide. However, nuclear power plants use the method of producing energy via nuclear fusion, and very dangerous accidents may occur due to radiation, nuclear waste, and so on. The Fukushima Nuclear Accident in 2011 showed the extent and impact of such danger. Therefore, the safety of nuclear plants and their containment building in particular have become a significant issue.

The containment buildings of nuclear power plants are generally designed and constructed with a structure of 1.2$\mathrm{m}$ thick reinforced concrete. If the concrete gets thicker, a high heat of hydration is generated inside the member due to exothermic hydration reaction of cement and binding material. The resulting difference in temperature between the inside and the outside of the member generates a temperature stress, increasing the probability of crack formation [1].

Also, as most nuclear power plant structures are located in coastal areas where it is easy to take and drain cooling water, the durability is highly likely to deteriorate owing to the action of chloride and sulfate, and neutralization. To solve this problem, the concrete produced by replacing some of the cement with admixtures such as fly ash and blast furnace slag was used for constructing existing nuclear power plants. However, the concrete mix generally used for nuclear power plants at present is designed and used with a rate of replacement of concrete with admixture that is noticeably lower than the standard maximum rate. Accordingly, for application to nuclear power plant structures, high-performance concrete produced by replacing some of the concrete with a large amount of admixtures to reduce the hydration heat and enhance the service life and the economic efficiency need to be developed and evaluated. 
In this study, we carried out an evaluation of shrinkage and durability of high-performance concrete applicable for constructing nuclear power plant structures, depending on the types of admixtures and the replacement rate. The target compressive strength of the concrete used is 6000 psi and 8000 psi, and the evaluation items are concrete compressive strength, chloride resistance, and freezing and thawing resistance.

\section{MiX DESIGN OF HPC}

The material that has the biggest portion in a nuclear power plant structure is concrete, and it is necessary to verify the performance of the concrete due to the dangers involved with the nuclear power plant structure. In particular, hydration heat reduction performance is one of the major requirements for the concrete used for nuclear power plant structures. For this reason, the blend cement produced by replacing $20 \%$ of the total weight with fly ash is used for domestic nuclear power plants. However, the hydration heat reduction effect achieved by replacement of $20 \%$ weight with fly ash is limited. Also, for the concrete that is simultaneously exposed to chemical attacks such as freezing/thawing and exposure to sea water, the mixing rate of fly ash is limited to a maximum $25 \%$ by the ACI 318-99 code [2]. Accordingly, in this study, the shrinkage and durability performance of the existing concrete mix for nuclear power plants (FA20) and those of the concrete mixes produced by replacing some of the concrete with diverse admixtures were compared and analyzed (Table 1).

TABLE 1. DETERMINATION OF MiXING Design

\begin{tabular}{|c|c|c|c|c|c|c|c|c|}
\hline Mix & \begin{tabular}{|c|} 
Compressive \\
Strength \\
(psi)
\end{tabular} & W/C & W & C & FA & BS & $\begin{array}{c}\text { Coarse } \\
\text { Agg }\end{array}$ & $\begin{array}{l}\text { Fine } \\
\text { Agg }\end{array}$ \\
\hline FA20 & \multirow{5}{*}{6000} & \multirow{5}{*}{40} & 162 & 324 & 81 & 0 & 1027 & 750 \\
\hline FA25 & & & 155 & 291 & 97 & 0 & 1044 & 762 \\
\hline BS25FA25 & & & 155 & 194 & 97 & 97 & 1041 & 760 \\
\hline BS30FA30 & & & 155 & 155 & 117 & 116 & 1037 & 757 \\
\hline BS50 & & & 155 & 194 & 0 & 194 & 1054 & 769 \\
\hline FA25 & \multirow{4}{*}{8000} & \multirow{4}{*}{34} & 155 & 342 & 114 & 0 & 1078 & 667 \\
\hline BS25FA25 & & & 155 & 228 & 114 & 114 & 1073 & 664 \\
\hline $\mathrm{BS} 30 \mathrm{FA} 30$ & & & 155 & 182 & 137 & 137 & 1069 & 661 \\
\hline BS50 & & & 155 & 228 & 0 & 228 & 1090 & 674 \\
\hline
\end{tabular}

* W : Wather, C : Cement, FA : Fly Ash, BS : Blast Furnace Slag, SF : Silica Fume

* Notation Example: BS30FA25SF5 (blast-furnace slag 30\%, Fly Ash $25 \%$, and Silica Fume 5\% in a binder)

The types of the admixtures used are ground granulated blast furnace slag (BS) and fly ash (FA). The variables of the experiment are the mix designs of two-component and three-component system concrete depending on the types of admixtures and replacement rate corresponding to the target compressive strength.

For this experiment, the ordinary Portland cement (OPC), admixtures, and aggregate that satisfy the relevant ASTM code were used. The physical and chemical characteristics of the binding materials and the aggregate used for the experiment are shown in Table 2 and 3 respectively.
Table 2. Analysis of the Chemical Characteristics of the BINDING MATERIALS

\begin{tabular}{|c|c|c|c|c|}
\hline \multicolumn{2}{|c|}{ Item } & OPC & FA & BS \\
\hline \multicolumn{1}{|c|}{ Density $\left(\mathbf{g} / \mathbf{c m}^{\mathbf{3}}\right)$} & $\mathbf{3 . 1 5}$ & $\mathbf{2 . 3 5}$ & $\mathbf{2 . 9 4}$ \\
\hline \multirow{4}{*}{$\begin{array}{c}\text { Chemical } \\
\text { composition }\end{array}$} & $\mathbf{S i O}_{\mathbf{2}}$ & 21.55 & 64.02 & 36.04 \\
\cline { 2 - 5 } & $\mathbf{A l}_{\mathbf{2}} \mathbf{O}_{\mathbf{3}}$ & 5.31 & 19.89 & 15.79 \\
\cline { 2 - 5 } & $\mathbf{F e}_{\mathbf{2}} \mathbf{O}_{\mathbf{3}}$ & 3.56 & 4.45 & 0.45 \\
\cline { 2 - 5 } & $\mathbf{C a O}$ & 61.23 & 3.82 & 42.16 \\
\cline { 2 - 5 } & $\mathbf{M g O}$ & 3.74 & 1.09 & 3.94 \\
\cline { 2 - 5 } & $\mathbf{S O}_{\mathbf{3}}$ & 1.95 & -0.7 & 1.95 \\
\cline { 2 - 5 } & $\mathbf{K}_{\mathbf{2}} \mathbf{O}$ & 1.08 & 1.13 & 0.5 \\
\cline { 2 - 5 } & $\mathbf{N a}_{\mathbf{2}} \mathbf{O}$ & 0.13 & 1.04 & 0.22 \\
\cline { 2 - 5 } & $\mathbf{L O I}$ & 1.24 & 6.76 & - \\
\hline
\end{tabular}

TABle 3 CHARACTERISTICS OF THE AGgREGATE

\begin{tabular}{|c|c|c|}
\hline Item & $\begin{array}{c}\text { Coarse } \\
\text { aggregates }\end{array}$ & $\begin{array}{c}\text { Fine } \\
\text { aggregates }\end{array}$ \\
\hline Origin and manufacturer & Shin Uljin & Shin Uljin \\
\hline Density $\left(\mathbf{g} / \mathbf{c m}^{\mathbf{3}}\right)$ & 2.77 & 2.68 \\
\hline Absorption ratio $\mathbf{( \% )}$ & 1.33 & 2.8 \\
\hline $\mathbf{0 . 0 8 m m ~ P a s s i n g ~ c o n t e n t ~} \mathbf{( \% )}$ & 0.91 & 4.8 \\
\hline Unit volume weight $\mathbf{( k g / \mathbf { m } ^ { \mathbf { 3 } } )}$ & 1.702 & 1.662 \\
\hline
\end{tabular}

\section{EXPERIMENT RESULT}

\section{A. Compressive Strength of Concrete}

The compressive strength test for concrete was carried out by applying the test method ASTM C39 [3]. The results of compressive strength test for different the types of admixtures and replacement rates are as shown in Figure 1 . The $91^{\text {st }}$ day compressive strengths of all mixes were either $6000 \mathrm{psi}$ or $8000 \mathrm{psi}$, and the target compressive strengths. In particular, the $91^{\text {st }}$ day compressive strengths of the mixes BS25FA25 and BS50 were about 1.2 times higher than that of the existing conventional mix used for constructing nuclear power plants (FA20).

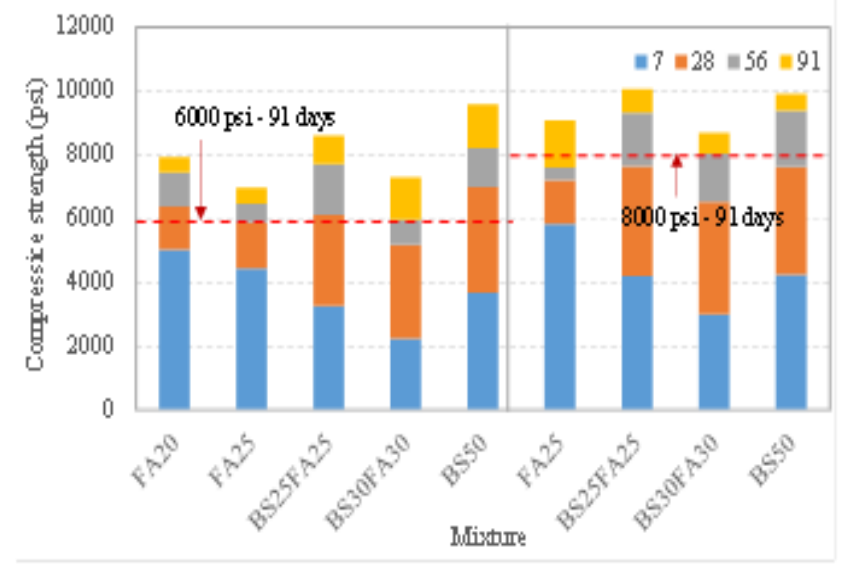

FIGURE 1. TEST RESULTS OF COMPRESSIVE STRENGTH 


\section{B. Evaluation of the Freezing and Thawing Resistance Performances}

The freezing and thawing resistance test was conducted by conducting measurements at the 150th and 300th cycles, respectively, after producing specimens in accordance with ASTM C666 [4]. Mass loss rate means the loss of mass caused by exfoliation of the concrete surface resulting from freezing and thawing, and the lower the mass loss rate is, the better the freezing and thawing resistance is [5, 6]. Also, the durability factor of concrete can be calculated by measuring the relative dynamic modulus(Figure 2). If the relative dynamic modulus is 60 or higher after 300 cycles of freezing and thawing, the freezing and thawing resistance can be determined to be excellent.

With the exception of the BS30FA30 mix and BS25FA25 mix with the target compressive strength of $6000 \mathrm{psi}$ and $8000 \mathrm{psi}$, respectively, the mass loss rates of all the mixes subjected to freezing and thawing were measured to be less than $2 \%$, showing their excellent performances. Also, the durability factors of most specimens were measured to be 90 or higher at the $300^{\text {th }}$ cycle irrespective of their compressive strength showing very high freezing and thawing resistances. Further, the durability factor of the BS25FA25 mix at 8000 psi was measured to be about 78, lower than those of other mixes by about $18 \%$. Though the air content of the concrete stable against freezing and thawing is $4-4.5 \%$ generally, the air content of the 8000 psi BS25FA25 mix was $3.5 \%$, which is relatively low. This is thought to be one of the reasons for the deterioration in the freezing and thawing resistance of the 8000 psi BS25FA25 mix.

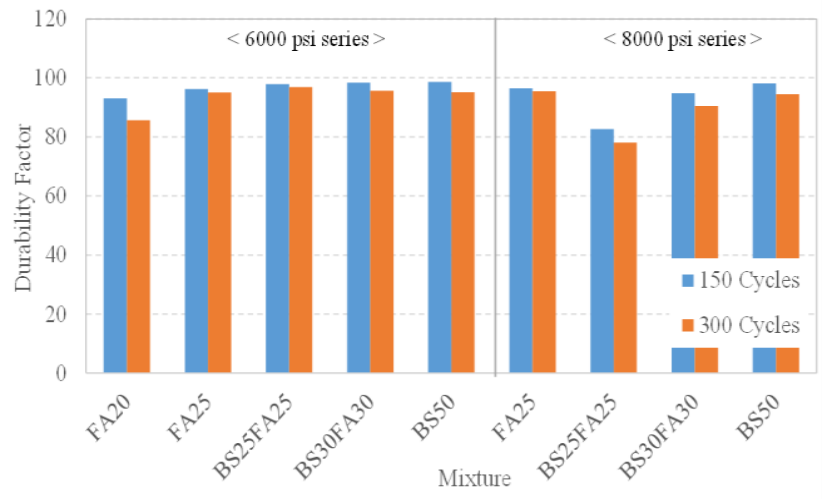

FIGURE2. EvaluATION OF FREEZING AND THAWING RESISTANCE PERFORMANCE

\section{Evaluation of Salt Damage Resistance Performance}

The experiment for evaluating the resistance to infiltration of chloride ions was carried out in accordance with the accelerated test method [7], and the salinity dispersion coefficients at different material ages $(28,91$, and 180 days) were measured. The main causes for deterioration in the lifespan of nuclear power plant structure are the saltinduced damage and other deterioration factors inside the concrete. For this reason, it is necessary to ensure the salt damage resistance performance of the concrete used in constructing nuclear power plant structures. The chloride dispersion coefficients for different experiment variables are shown in Table 4.
The chloride dispersion coefficient of the 8000 psi mix showed a noticeably decreasing trend in comparison to that of the 6000 psi mix. In particular, the chloride dispersion coefficient of the BS50 mix was shown to be the lowest irrespective of the compressive strength, and that of the three-component system concrete was shown to be relatively high. Consequently, it can be inferred that high strength is advantageous in developing salt damage resistance, and use of BS is more advantageous than the use of FA [8, 9].

TABLE 4. EVALUATION OF SALT DAMAGE RESISTANCE PERFORMANCE

\begin{tabular}{|c|c|c|c|c|}
\hline \multirow{2}{*}{$\begin{array}{c}\text { Compressive } \\
\text { Strength }\end{array}$} & Mix Type & 28 Day & 91 Day & 180 Day \\
\cline { 2 - 5 }$\left(\times 10^{-12} \mathrm{~cm}^{2} / \mathrm{s}\right)$ \\
\hline \multirow{4}{*}{$6000 \mathrm{psi}$} & FA20 & 18.98 & 6.46 & 5.76 \\
\cline { 2 - 5 } & FA25 & 22.99 & 7.25 & 6.29 \\
\cline { 2 - 5 } & BS25FA25 & 11.03 & 4.31 & 2.41 \\
\cline { 2 - 5 } & BS30FA30 & 22.29 & 5.22 & 1.76 \\
\cline { 2 - 5 } & BS50 & 9.06 & 2.68 & 2.56 \\
\hline \multirow{3}{*}{8000 psi } & FA25 & 16.16 & 4.26 & 2.06 \\
\cline { 2 - 5 } & BS25FA25 & 8.07 & 2.75 & 2.29 \\
\cline { 2 - 5 } & BS30FA30 & 10.51 & 3.14 & 1.33 \\
\cline { 2 - 5 } & BS50 & 5.08 & 2.27 & 2.09 \\
\hline
\end{tabular}

\section{Shrinkage}

An experiment was carried out in accordance with the ASTM C 596 code to measure the change in the shrinkage of concrete depending on the material age [10]. Among the experiment variables, the shrinkage of the threecomponent system mix was shown to be the lowest. The difference between the dry shrinkages of the BS25FA25 mix and the BS30FA30 mix was insignificant. On the other hand, the dry shrinkages of FA25 and BS50 mixes were high irrespective of the target compressive strength, and were about 1.5 times higher than that of the threecomponent system concrete. However, the $91^{\text {st }}$ day dry shrinkages of all the mixes were shown to be not higher than $800 \mu \varepsilon$, which satisfies the contraction crack reduction goal of JASS5 of the Architectural Institute of Japan, which was set to secure durability.

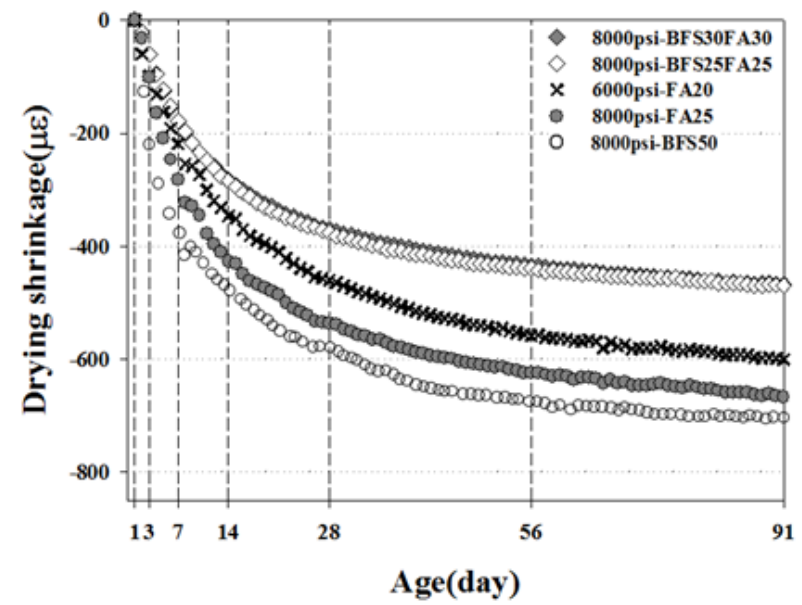

FiguRE 3. ReSUlt OF DRY SHRINKAGE MEASUREMENTS (8000 PSI) 


\section{CONCLUSION}

By measuring and analyzing the durability and dry shrinkage of the concrete mixes for construction of nuclear power plant structures, produced by replacing some of the cement with diverse admixtures, the following conclusions were drawn:

All the concrete mixes produced by replacing some of the cement with fly ash and blast furnace slag showed performances equal to or higher than the target compressive strength, and the BS50 mix showed the highest compressive strength. With respect to freezing and thawing resistance, all the mixes showed performances equal to or higher than the target irrespective of the variables. In particular, freezing and thawing resistance was affected more by the concrete air content than by the types of admixtures and the replacement rate. In the case of salt damage resistance, the higher the strength was, the lower the chloride permeability coefficient was, and the resistance of the concrete produced by replacing some of the cement with blast furnace slag was higher. Though the dry shrinkage of the three-component system concrete was shown to be the lowest, the $91^{\text {st }}$ day dry shrinkage of all the mixes satisfied the contraction crack reduction goal showing values of $800 \mu \varepsilon$ or lower.

Thus, for constructing nuclear power plant structures, the concrete mix produced by replacing some of the concrete with the blast furnace slag showed a performance equal to or higher than that of the existing FA20 mix. In particular, the BS50 mix that shows the lowest chloride permeability coefficient was most suitable for constructing nuclear power plant structures located in coastal areas where it is easy to take and drain cooling water.

\section{ACKNOWLEDGMENT}

This work was supported by the Nuclear Power R\&D Program of the Korea Institute of Energy Technology Evaluation and Planning (KETEP) grant funded by the Korea government Ministry of Knowledge Economy (No. 2014151010169A).

\section{REFERENCES}

[1] Mehta P.K. Durability of concrete-fifty years of progress. In: Durability of Concrete: Second International Conference, Montreal, Canada 1991. ACI SP-126; 1991. pp. 1-132.

[2] ACI 318 Committee, Building Code Requirements for Reinforced Concrete, ACI, 1999, pp.35-3.

[3] ASTM C 39, Compressive strength of cylindrical concrete specimens, 2012.

[4] ASTM C 666, Resistance of Concrete to Rapid Freezing and thawing, In Annual Book of ASTM Standards, 1984.

[5] Park K.P., Kim S.S., Lee S.T., Kim J.P., Jung H.S. Properties on the Freeze-Thaw of Concrete Subjected to Seawater Attack, Journal of the Korea Concrete Institute, Vol.23, No.1, 2011, pp.23-30.

[6] Aitcin P-C, Pigeon M, Pleau R, Gagne R. Freezing and thawing durability of high performance concrete. In: Proceedings of the International Symposium on High-Performance Concrete and Reactive Powder Concretes, Sherbrooke 98, vol. 4. 1998. pp. 383-91.

[7] NT Build 492: Chloride Migration Coefficient from Nonsteadystate Migration Experiments

[8] Yon E.S., Lee T.W., Park S.B. Analysis of Correlation between Compressive Strength, Void Ratio and Chloride Diffusion Coefficient of Concrete Using Various Kinds of Cement, Journal of the Korea Concrete Institute, Vol.17, No.5, 2005, pp.735-742.

[9] Neville A.M. Properties of Concrete, Addison Wesley Longman, 1995, 844 pp.

[10] Kutti T., Berntsson L., Chandra S. Shrinkage of Cements with High Content of Blast Furnace Slag, in Malhotra V. M. (Ed.), Proceedings of Fourth CANMET/ACI International Conference on Fly Ash, Slag and Natural Pozzolans in Concrete, 1992, pp. 615625 . 